\title{
Role of Topical Application of Growth Factors on Periodontal Repair
}

\author{
Athraa Yahya Al-Hijazi, Abdul Karim Abed Ali Al-Mahammadawy \\ Department of Oral Diagnosis, College of Dentistry, University of Baghdad, Baghdad, Iraq \\ Email: athraayms@yahoo.com
}

Received 16 December 2013; revised 16 January 2014; accepted 23 January 2014

Copyright (C) 2014 by authors and Scientific Research Publishing Inc.

This work is licensed under the Creative Commons Attribution International License (CC BY). http://creativecommons.org/licenses/by/4.0/

\section{(c) (i) Open Access}

\section{Abstract}

Reconstruction of lost or injured periodontal tissues in such a way that both the original structures and their function are completely restored. Restoring of lost periodontal tissues involves a creation of new attachment, including the formation of a new periodontal ligament with its fibers inserted in newly formed cementum and alveolar bone. The purpose of this research is to illustrate the biological actions of topical application of growth factors TGF- $\beta 1$, VEGF on periodontal cells and tissues, which are involved in periodontal regeneration. Fifty-four male Albino rats were subjected for non surgical operation of distal sides of both lower anterior teeth, right side was considered as experimental site treated with $1 \mu \mathrm{m}$ of VEGF, TGF- $\beta 1$, while left side treated with 1 $\mu \mathrm{m}$ of normal saline as a control one. All the samples were studied histologically and histometry at three interval periods $3,7,14$ days postoperatively. The results demonstrated that the mean value of amount of new bone and the mean of the length of junctional epithelia is showed to be higher in VEGF group, while the mean of periodontal ligament width and mean of rate of bone maturation are reported to be higher in combination group. High mean value for the width of cellular cementum is recorded in TGF group. Conclusion: The present study suggested that growth factors application in injured periodontium have a role in periodontal healing and VEGF illustrates to be the most powerful one.

\section{Keywords}

Vascular Endothelial Growth Factor; Periodontium Healing; Transforming Growth Factor

\section{Introduction}

Regeneration of periodontal structures lost during periodontal diseases constitutes a complex biological process regulated among others by interactions between cells and growth factors. 
The histological feature of a periodontal wound comprises 1) the gingival epithelium, 2) the gingival connective tissue, 3) the periodontal ligament, and the hard tissue components such as 4) alveolar bone and 5) cementum or dentin on the dental root surface [1].

Growth factors are biologically active polypeptides affecting the proliferation, chemotaxis and differentiation of cells from epithelium, bone and connective tissue. They express their action by binding to specific cell-surface receptors present on various target cells including osteoblasts, cementoblasts and periodontal ligament fibroblasts [2] [3]. It is also found that several growth factors in addition to cytokines and enzymes, of host origin appear to hold the greatest promise as valuable biomarkers in assessing the health of periodontal tissue, and its role in periodontial healing [4]-[6]. Growth factors mediate many events associated with turnover, repair and regeneration of periodontal tissues. Vascular Endothelial Growth Factor (VEGF). Over the last two decades researchers have demonstrated that VEGF is a key regulator of physiological and pathological angiogenesis, because it induces endothelial cell proliferation, stimulates angiogenesis and increases vascular permeability [7]. Transforming growth factor- $\boldsymbol{\beta}$ (TGF- $\boldsymbol{\beta}$ ) exhibits both pro-inflammatory and anti-inflammatory properties besides its ability to stimulate synthesis of ECM molecules and to inhibit the breakdown of ECM, it has been intensively evaluated in relation to periodontial healing [8].

The observation that growth factors participate in all cell functions led to exogenous application during periodontal tissue repair high lightened on the present research aim to use growth factors as an alternative therapeutic approach to periodontal treatment.

\section{Materials and Methods}

\subsection{Materials}

VEGF165Aprotein (Rat) (ab51967), lyophilised form From abcam company. TGF beta 1 protein (Active) (ab50036), lyophilised form From abcam company.

\subsection{Study Design}

All experimental procedures were carried out in accordance with the ethical principles of animal experimentation and according to the National Research Council's guide for the care and use of laboratory animals. In this experimental study fifty four male Albino rats, weighting (300 - 400) gram, aged (6 - 8) months were used and maintained under control conditions of temperature, drinking and food consumption. The animals were subjected for non surgical operation of distal sides of both lower anterior teeth (right side was considered as experimental site, while left be the control one).

The animals were divided into control and experimental group, the experimental group was subdivided into following groups according to the applicated growth factors.

A. Contol group the periodontium defect treated with $1 \mu \mathrm{m}$ of normal saline and its number represented the all number of the following experimental groups as the left side of each animal considered to be the control.

B. Experimental group includes:

- Group 1 contains (18) rats, the periodontium defect treated with $1 \mu \mathrm{m}$ of VEGF.

- Group 2 contains (18) rats the periodontium defect treated with $1 \mu \mathrm{m}$ of TGF- $\beta 1$.

- Group 3 contains (18) rats, the periodontium defect treated with $1 \mu \mathrm{m}$ combination of (VEGF \& TGF- $\beta 1$ ).

\subsection{Methods}

\subsubsection{Assessment for the Subgingival Depth to Create a Periodontium Defect}

Before starting the experiment, histologic and radiographic examinations were done to ten samples of lower jaw carrying the central teeth of normal intact rats (excluded from the designed number) to get a data base on the estimation of a proper sub gingival depth related to rats that allowed and supported the study to create a periodontium defect includes alveolar bone, cementum and periodontal ligament (Figure 1).

\subsubsection{Non Surgical Technique}

The non surgery was performed under a well sterilized condition and gentle technique. Every animal was weighted to calculate the dose of general anesthesia that was given to it. The general anesthesia was induced by Intra muscular injection of xylazine 2\% (0.4 mg/kg B.W.), plus keta mine HCL $50 \mathrm{mg}$ (40 mg/kg-B.W.). Then 


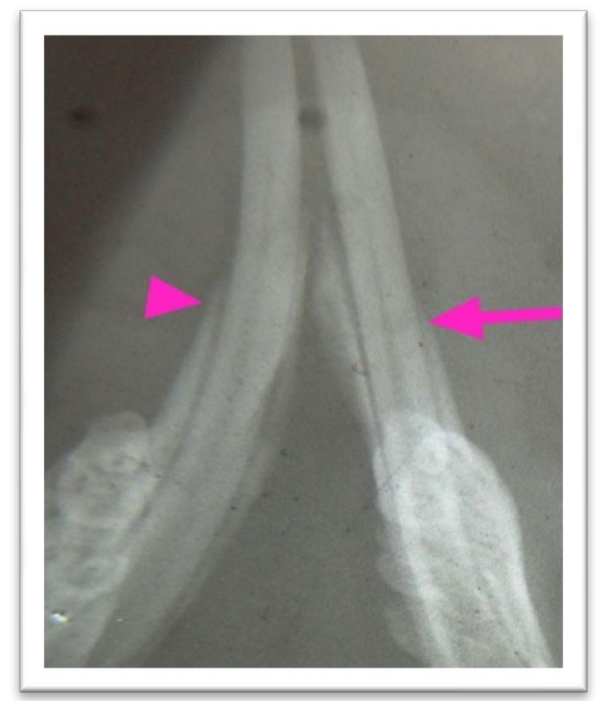

Figure 1. Radiographic view for lower anterior teeth shows cutting $(0.2$ $\mathrm{mm}$ ) from alveolar bone (arrow) while other side still intact (arrow head).

the animal was placed on the surgical table and the surgical towel was placed under the site of the operation. Using Cavitron Ultrasonic Scaler with a stopper to $0.2 \mathrm{~mm}$ (depth assess from our present data) and with focused spray design that inserts direct water down into the pocket in which it helps to flush away debris., periodotium defect was made. Removing thin cementum layer, alveolar bone layer and tearing in periodontal ligament for both distal sides of lower anterior teeth, experimental and control sites. After operation a radiographic films were taken to confirm our work (Figure 1).

Drying the area by air, then applied of growth factor (VEGF, TGF- $\beta 1$, combination) $1 \mu \mathrm{m}$, while normal saline $1 \mu \mathrm{m}$ was used for control. The animals were scarified at intervals 3, 7, 14 day postoperatively, using over dose anesthesia. Six animals for each period. Jaw were removed, and the lower jaw carrying anterior teeth was dissected.

\subsubsection{Preparation of the Specimens}

The specimens were immediately fixed in $10 \%$ freshly prepared neutral buffered formalin for 3 days, then decalcified by formic acid-sodium citrate solution, which was prepared freshly from 2 solutions:

Solution A: 125 cc formic acid 90\%. 125 cc distilled water.

Solution B: $50 \mathrm{mg}$ sodium citrate. 250 cc distilled water.

Then passing to all laboratory procedures till getting slides stained by hematoxylin and eosin (H \& E) and examined under light microscope for histological evaluation.

\subsubsection{Histometry Evaluation of Histological Findings}

A. Periodontal ligament width. Measured the distance of periodontal ligament present in cervical area (only) passed from the alveolar bone to cementum.

B. Junctional epithelial length (JEP) measured as the distance between the most coronal to the most apical aspects of the epithelium along the root.

C. Newly formed cementum and bone width (in cervical area), measured from the reversal line separated the old from the new one, to its final edge of the newly apposite tissue.

The above measures were obtained through Olympus light microscope equipped with eyepiece ocular scale micrometer at $20 \times$ magnification

D. Rate of maturation of newly bone was estimated by counting the number of osteon in five histological sections per animal and in five microscopic fields for each section, in cervical region, at $40 \times$ magnification [9].

\subsubsection{Statistic Analysis}

A. Descriptive data analysis. B. Inferential data analysis. 


\section{Results and Discussion}

\subsection{Histological Findings}

Histological results for control group illustrated deposition of osteoid tissue against alvrolar bone, Seconday junctional epithelia and fibrous junctional are detected in Figures 2, 3, 4, while for VEGF group osteoclast detected early at 3 day and then immature bone apposed against the alveolar bone with identification of reversed

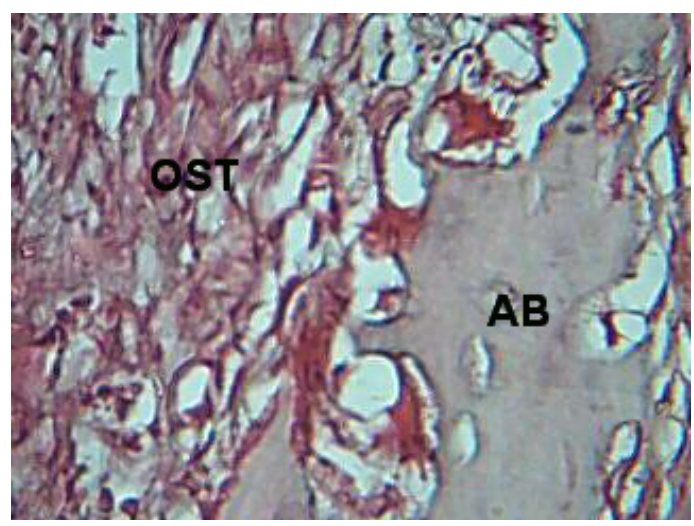

Figure 2. View for osteoid tissue (OST), alveolar bone $(\mathrm{AB})$ in control group at 7 days. $\mathrm{H} \& \mathrm{E} \times 40$.

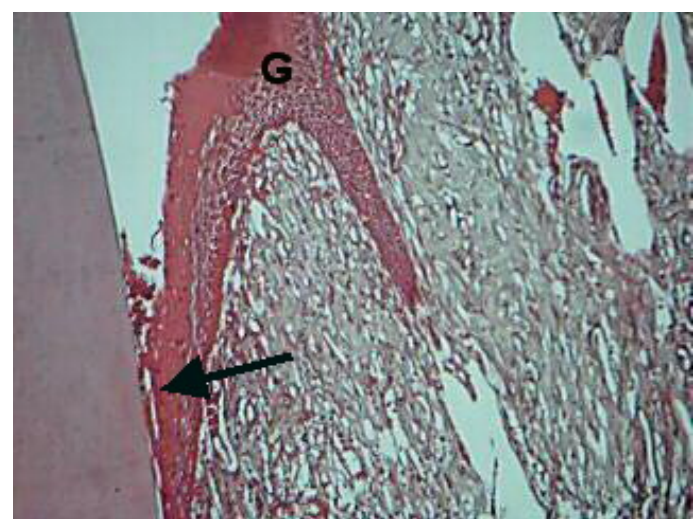

Figure 3. View for periodontium (control) at 14 day duration, shows establishment of secondary junctional epithelia (arrow), gingiva (G) H \& E ×20.

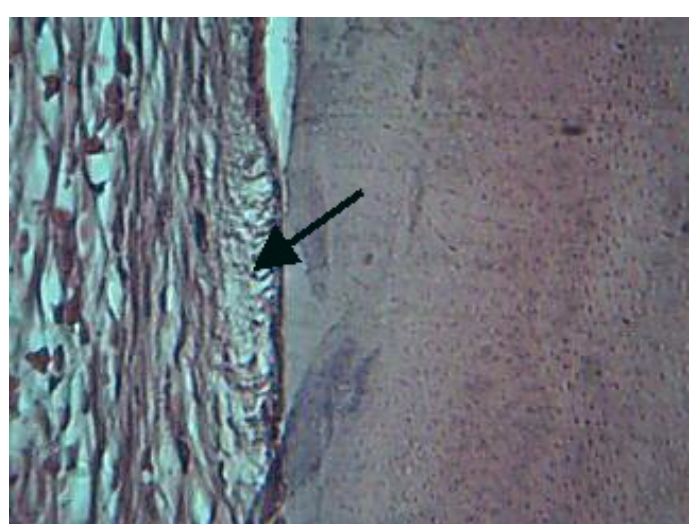

Figure 4. view illustrates fibrous junctional site (arrow) in control. H \& E $\times 20$. 
line. The new cellular cementum, periodontal ligament and junctional epithelia reestablished at 14 day, Figures $5,6,7,8,9$. TGF B1 group shows gingivae with active mitotic feature for basal cell and apposition of cellular cemntum is detected, Figures 10, 11, while combination group shows mature bone newly formed separated by demarked line from the old bone, Figure 12.

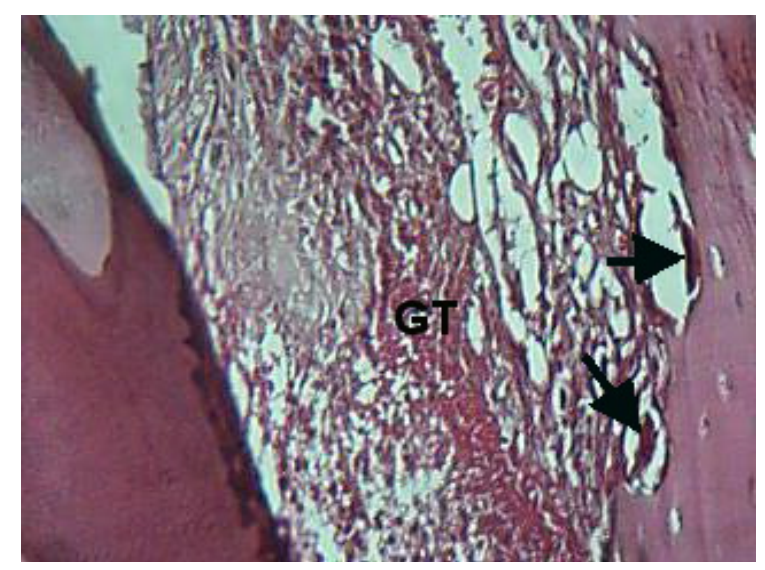

Figure 5. View for granulation tissue (GT) with presences of osteoclast (arrow) in VEGF group at 3 day. $\mathrm{H} \& \mathrm{E} \times 20$.

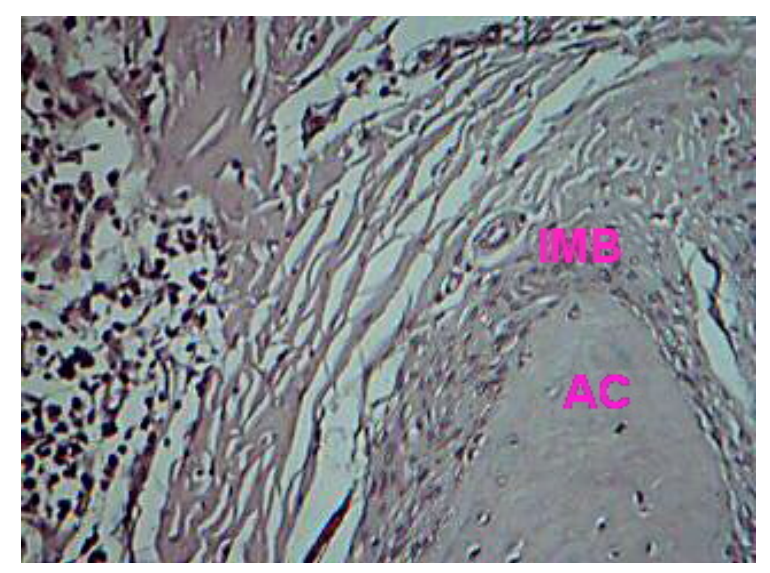

Figure 6. Histological view for periodontium treated with VEGF at 14 days, shows immature bone (IMB) overlay alveolar crest (AC). H \& E ×20.

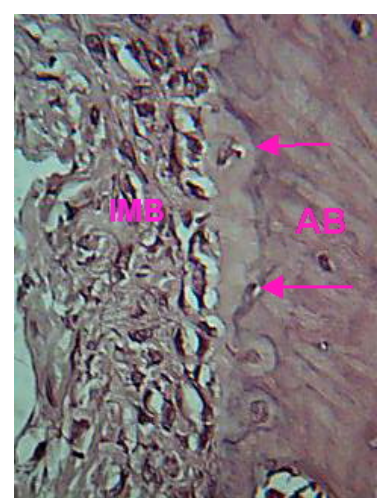

Figure 7. Magnifying view for VEGF group shows immature bone (IMB), alveolar bone (AB) with presences of reversal line (arrow). H \& E $\times 20$. 


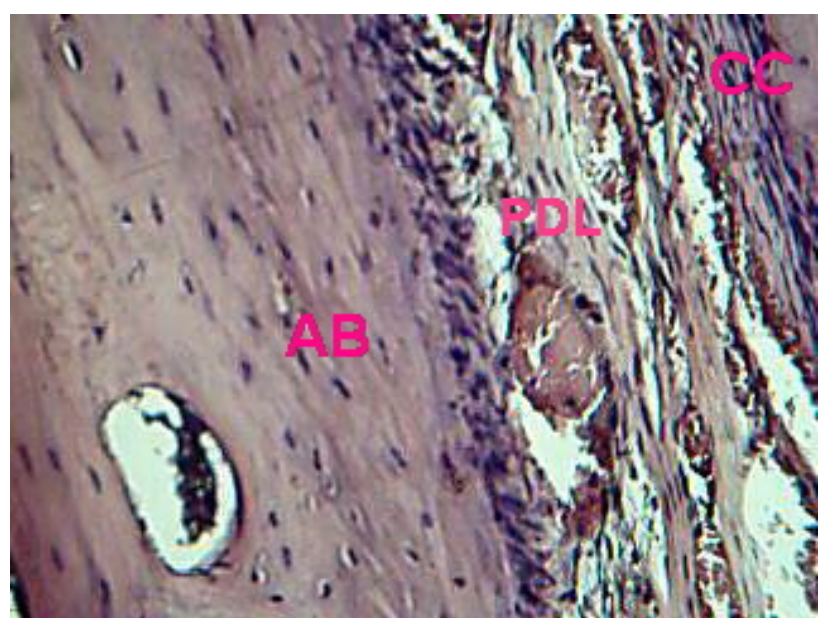

Figure 8. View illustrates reestablishment of periodontal ligament (PDL), cellular cementum (CC) and alveolar bone (AB) in VEGF group. $\mathrm{H} \& \mathrm{E} \times 20$.

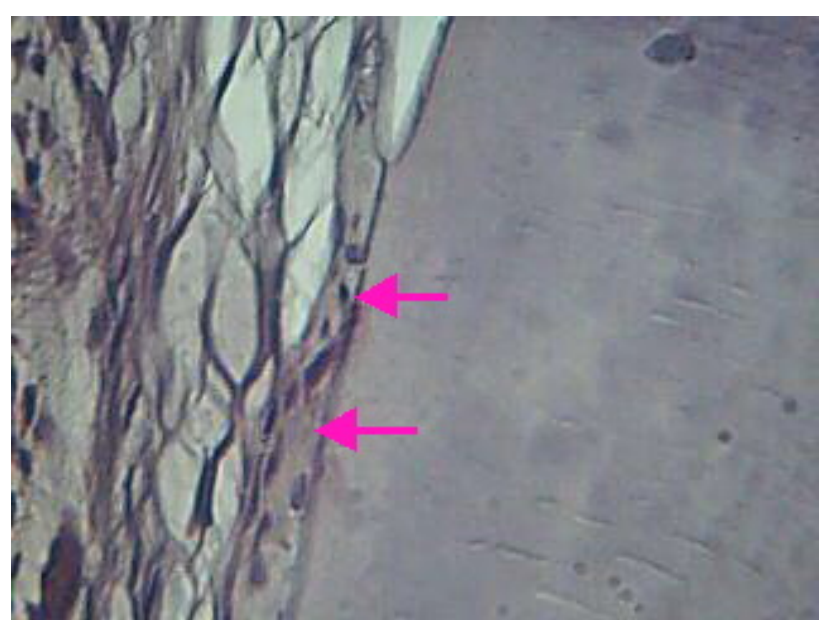

Figure 9. View for establishment of junctional epithelia (arrow) In VEGF group. $\mathrm{H} \& \mathrm{E} \times 40$.

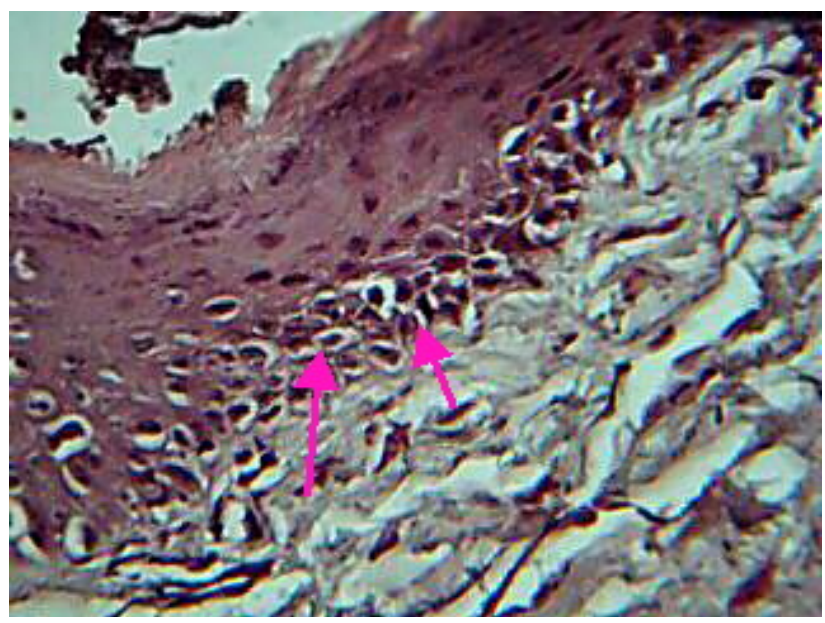

Figure 10. View for gingival tissue in TGF group, at 3 day, shows mitotic activity of basal cell. H \& E $\times 20$. 


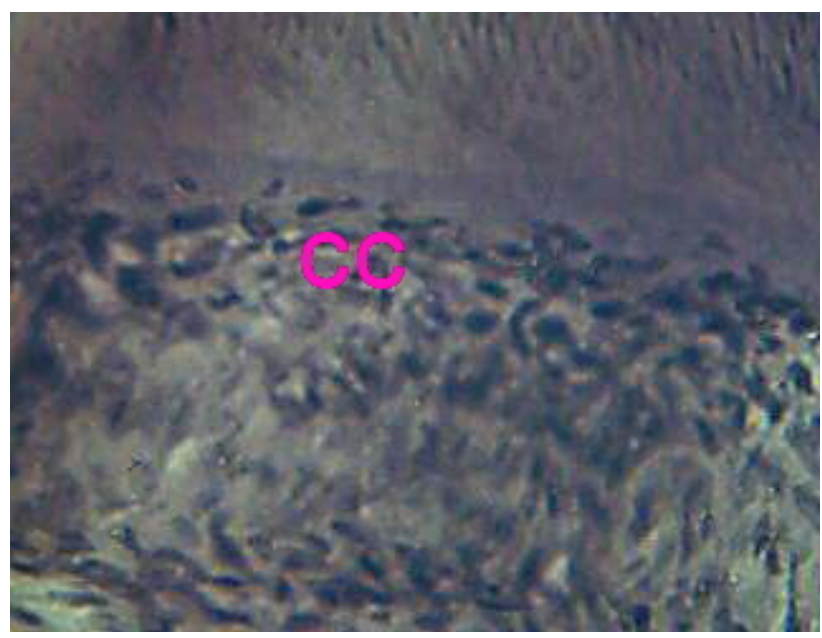

Figure 11. Magnifying view for cellular cementum (CC) in TGF group. $\mathrm{H} \& \mathrm{E} \times 40$.

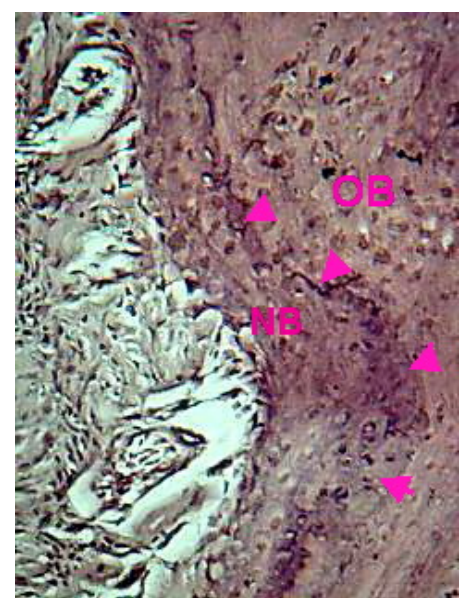

Figure 12. View for periodontium treated with combination after curette at 14 day duration shows new bone formation (NB) separated from old bone (OB) by reversal line (arrow head) $\mathrm{H}$ $\& \mathrm{E} \times 20$.

The present results conclude the followings:

a. All study groups (control, VEGF treated group, TGF $\beta 1$ treated group and combination (VEGF \& TGF) group), show organized blood clot and formation of granulation tissue at 3 day period.

b. Edematous gingival identified in control and VEGF groups, While TGF and combination groups illustrate gingiva with mitotic basal cells. This result may contributed to that VEGF cause hyperpermeability, which allows fluid to leak from the intravascular space into the parenchyma tissue, which causes vasogenic edema and increased interstitial fluid pressure [10], while results demonstrated that the maintenance and proliferation of germ stem cells and their progeny depends upon TGF B1 [11].

c. Osteoclast cell identify early in VEGF only, while osteoid tissue recognized early in combination group. These findings suggest that VEGF may regulate osteoclast differentiation as well as angiogenesis [12], while TGF-beta has been shown to be one of the most important regulators in chondrogenesis and osteogenesis [13].

d. Mature bone detected in combination group only, at 14 day period, other groups show immature form. This finding demonstrated the mechanisms in which TGF- $\beta 1$ interacts with bone component cells, such as osteoblasts, osteoclasts, mesenchymal stem cells, and hematopoietic stem cells, in concert with other cytokines and hormones [14].

e. Secondary junctional epithelia recognized in control group only, at 14 day period. 
Our study suggest that this observation may be a tissue response to injury, which may lead to fiber interdigitation in curette area that lack junctional epithelia. This result is in agreement with findings of Tal \& Stahl [15].

\subsection{Histometrical Analysis}

Bar chart and Stem-Leaf (Explorer) Plots for mean values of Periodontal ligament width, Junctional epithelial length, new cementum width, new bone width and rate of maturation are listed in (Table 1; Figures 13 and 14) The histometric data records the followings.
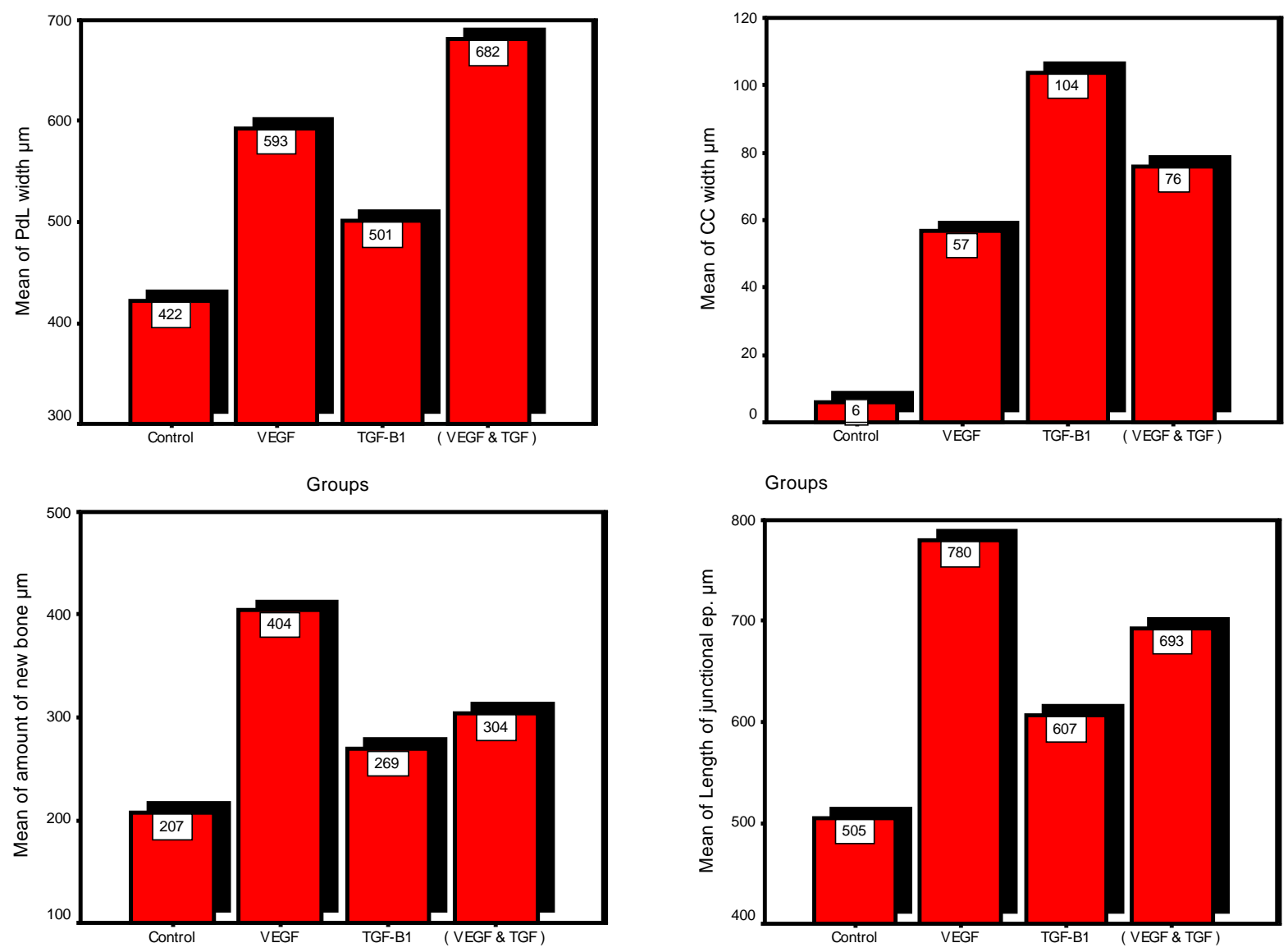

Groups

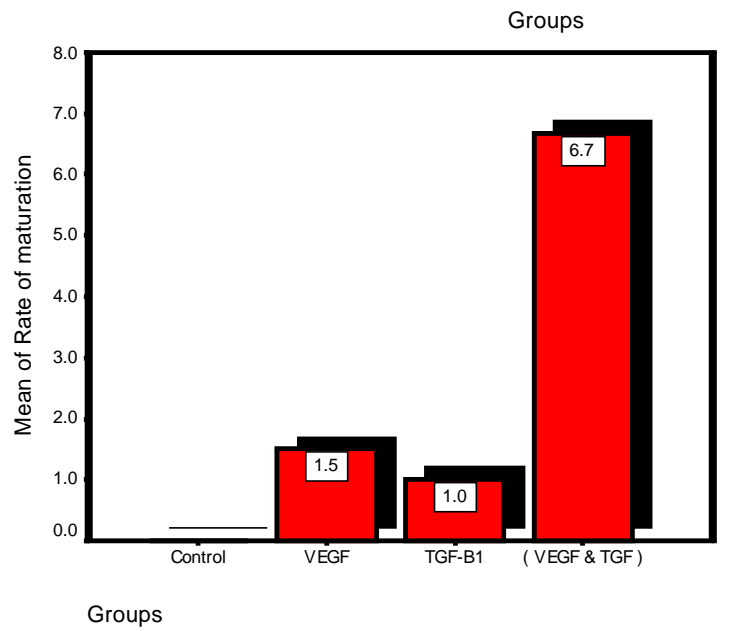

Figure 13. Bar charts of means values for the histometry of histological findings at 14 days parameters at the studied trials. 

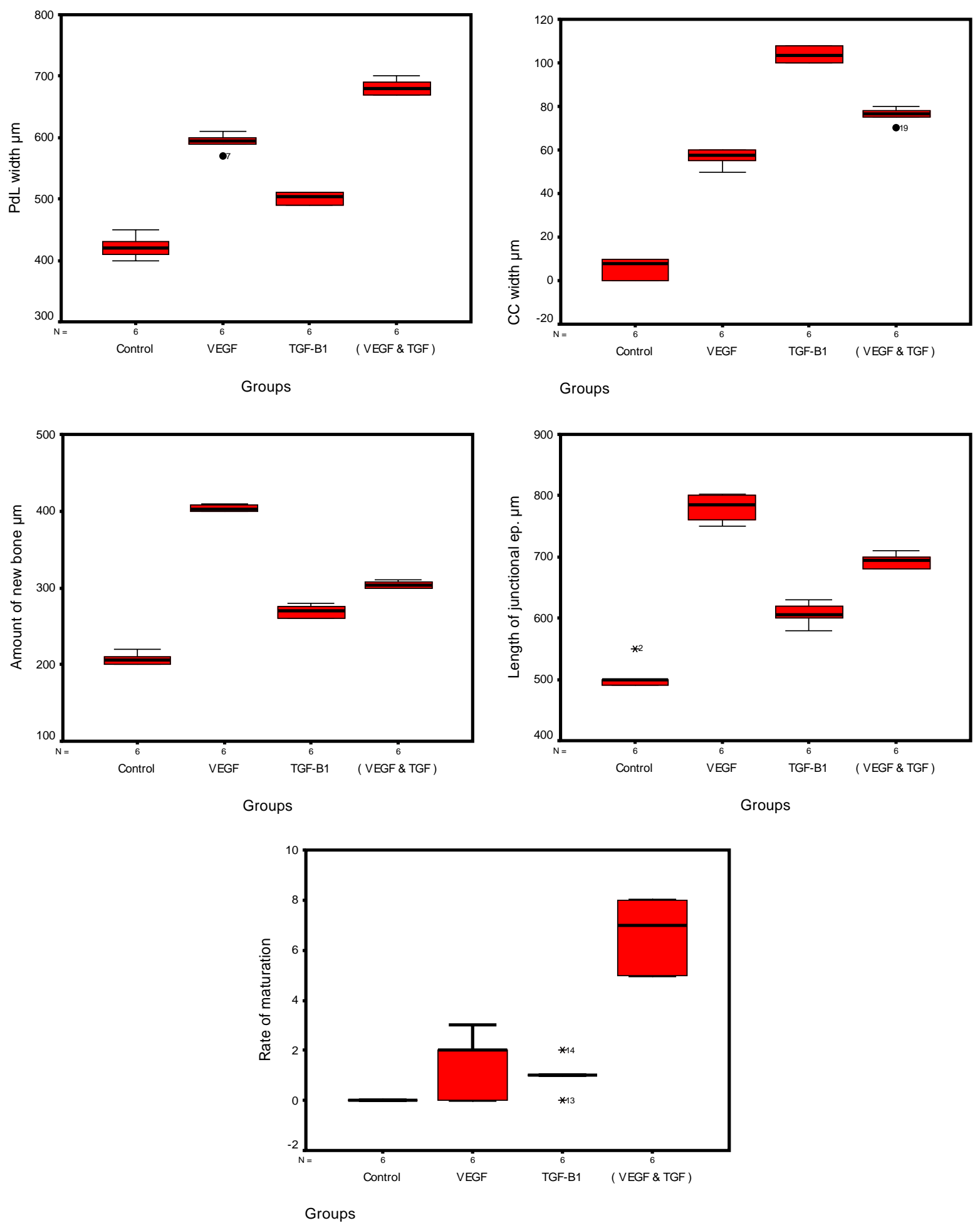

Figure 14. Stem-leaf (explorer) plots according to histometry of histological findings at 14 days parameters in studied trials.

1. The mean value of amount of new bone and the mean of the length of junctional epithelia is showed to be higher in VEGF group, this agrees with a previous study [16] in which reduction in width of an intrabony periodontal defect was accompanied by a long junctional epithelia.

2. The mean of periodontal ligament width and mean of rate of bone maturation are reported to be higher in 
Table 1. Multiple comparisons among all pairs for histometry of histological findings at 14 days parameters at the studied trials.

\begin{tabular}{|c|c|c|c|c|c|c|}
\hline \multirow[b]{2}{*}{ Group I } & \multirow[b]{2}{*}{ Group J } & \multicolumn{5}{|c|}{ Sig. Levels } \\
\hline & & PdL width & C.C. width & $\begin{array}{l}\text { Amount of } \\
\text { new bone }\end{array}$ & $\begin{array}{l}\text { Length of } \\
\text { Junctional }\end{array}$ & $\begin{array}{c}\text { Rate of } \\
\text { maturation }\end{array}$ \\
\hline \multirow{3}{*}{ Control } & VEGF & 0.000 & 0.000 & 0.000 & 0.000 & 0.019 \\
\hline & TGF- $\beta 1$ & 0.000 & 0.000 & 0.000 & 0.000 & 0.105 \\
\hline & (VEGF \& TGF) & 0.000 & 0.000 & 0.000 & 0.000 & 0.000 \\
\hline \multirow{2}{*}{ VEGF } & TGF- $\beta 1$ & 0.000 & 0.000 & 0.000 & 0.000 & 0.406 \\
\hline & (VEGF \& TGF) & 0.000 & 0.000 & 0.000 & 0.000 & 0.000 \\
\hline TGF- $\beta 1$ & (VEGF \& TGF) & 0.000 & 0.000 & 0.000 & 0.000 & 0.000 \\
\hline
\end{tabular}

${ }^{(*)}$ HS: Highly Significant at $\mathrm{P}<0.01$; NS: Non Significant at $\mathrm{P}>0.05$.

combination group. This is due to effect of both VEGF and TGF for enhancement of cellular proliferation by TGF and nourishment of the developing repaired area by newly blood vessels that formed in response to VEGF action.

\section{Conclusion}

The present study suggested that all experimental groups with growth factors application show repaired periodontium higher than control groups and it seems that single use of VEGF in injured periodontium is a more powerful tool in regeneration than TGF $\beta 1$ or their combination.

\section{References}

[1] Zia, A., Khan, S., Bey, A., Gupta, N.D. and Mukhtar-Un-Nisar, S. (2011) Oral Biomarkers in the Diagnosis and Progression of Periodontal Diseases. Biology and Medicine, 3, 45-52.

[2] Kaufman, E. and Lamster, I.B. (2000) Analysis of Saliva for Periodontal Diagnosis: A Review. Journal of Clinical Periodontology, 27, 453-465. http://dx.doi.org/10.1034/j.1600-051x.2000.027007453.x

[3] Giannobile, W.V., Al-Shammari, K.F. and Sarment, D.P. (2003) Matrix Molecules and Growth Factors as Indicators of Periodontal Disease Activity. Periodontology, 31, 125-134. http://dx.doi.org/10.1034/j.1600-0757.2003.03108.x

[4] Gürkan, A., Emingil, G., Cinarcik, S. and Berdeli, A. (2006) Gingivalcrevicular Fluid Transforming Growth FactorBeta1 in Several Forms of Periodontal Disease. Archives of Oral Biology, 51, 906-912. http://dx.doi.org/10.1016/j.archoralbio.2006.04.008

[5] Gonçalves, R.P., Damante, C.A., Moura Lima, F.L., Imbronito, A.V., Daumas Nunes, F. and Pustiglioni, F.E. (2009) Detection of MMP-2 and MMP-9 Salivary Levels in Patients with Chronic Periodontitis before and after Periodontal Treatment. Revista Odonto Ciência, 24, 264-269.

[6] Pisoschi, C., Banita, M., Stanciulescu, C., Fusaru, A.M. and Gheorghita, M. (2009) Influence of Some Mediators of Extracellular Matrix Remodeling on Angiogenesis in Diabetic Gingival Overgrowth. FEBS Journal, 276, 217.

[7] Keles, G.C., Cetinkaya, B.O., Eroglu, C., Simsek, S.B. and Kahraman, H. (2010) Vascular Endothelial Growth Factor Expression Levels of Gingiva in Gingivitis and Periodontitis Patients with/without Diabetes Mellitus. Inflammation Research, 59, 543-549. http://dx.doi.org/10.1007/s00011-010-0158-8

[8] Buduneli, N. and Kinane, D.F. (2011) Host-Derived Diagnostic Markers Related to Soft Tissue Destruction and Bone Degradation in Periodontitis. Journal of Clinical Periodontology, 38, 85-105. http://dx.doi.org/10.1111/j.1600-051X.2010.01670.x

[9] Nemcovsky, C.E., Beny, L., Shanberger, S. and Feldman, H.S. (2004) Bone Apposition in Surgical Defects Following Orthodontic Movement. Journal of Periodontology, 75, 1021-1027. http://dx.doi.org/10.1902/jop.2004.75.7.1013

[10] Gerstner, E.R., Duda, D.G., di Tomaso, E., Ryg, P.A., Loeffler, J.S., Sorensen, A.G., Ivy, P., Jain, R.K. and Batchelor, T.T. (2009) VEGF Inhibitors in the Treatment of Cerebral Edema in Patients with Brain Cancer. Nature Reviews Clinical Oncology, 6, 229-236. http://dx.doi.org/10.1038/nrclinonc.2009.14

[11] Shivdasani, A. and Ingham, Ph. (2003) Regulation of Stem Cell Maintenance and Transit Amplifying Cell Proliferation by TGF- $\beta$ Signaling in Drosophila Spermatogenesis. Current Biology, 13, 2065-2072. http://dx.doi.org/10.1016/j.cub.2003.10.063 
[12] Niida, S., Kaku, M., Amano, H., Yoshida, H., Kataoka, H. and Nishikawa, S. (1999) Vascular Endothelial Growth Factor Can Substitute for Macrophage Colony-Stimulating Factor in the Support of Osteoclastic Bone Resorption. Journal of Experimental Medicine, 190, 293-298. http://dx.doi.org/10.1084/jem.190.2.293

[13] Olivos-Meza, A., Fitzsimmons, J., Casper, M. and Chen, Q. (2010) Pretreatment of Periosteum with TGF- $\beta 1$ in Situ Enhances the Quality of Osteochondral Tissue Regenerated from Transplanted Periosteal Grafts in Adult Rabbits. Osteoarthritis Cartilage, 18, 1183-1191. http://dx.doi.org/10.1016/j.joca.2010.06.003

[14] Kasagi, Sh. and Chen, W. (2013) TGF-Beta1 on Osteoimmunology and the Bone Component Cells. Cell \& Bioscience, 3, 2-7. http://dx.doi.org/10.1186/2045-3701-3-4

[15] Tal, H. and Stahl, S.S. (1986) Periodontal Attachment Responses to Surgical Injury in the Cat. Removal of Buccal Bone with and without Placement of Foreign Body at Ligament Periphery. Journal of Clinical Periodontology, 13, 4551. http://dx.doi.org/10.1111/j.1600-051X.1986.tb01413.X

[16] Polson, A., Caton, J., Polson, A.P., Nyman, S., Novak, J. and Reed, B. (1984) Periodontal Response after Tooth Movement into Infra-Bony Defects. Journal of Periodontology, 55, 197-202. http://dx.doi.org/10.1902/jop.1984.55.4.197

\section{Abbreviations}

VEGF: vascular endothelial growth factor

PDL: periodontal ligament

TGF- $\beta 1$ : transforming growth factor

CC: cellular cementum

AB: alveolar bone 